\title{
Reliability and validity study of a Brazilian- Portuguese version of the fatigue severity scale in Parkinson's disease patients
}

\author{
Validação e reprodutibilidade da versão brasileira da escala de gravidade de fadiga em \\ pacientes com doença de Parkinson
}

Silvia Valderramas', Ana Cristina Feres², Ailton Melo ${ }^{3}$

\begin{abstract}
The Fatigue Severity Scale (FSS) is one of the most frequently used self-rating scales for fatigue in Parkinson's disease (PD) and it lacks a validated Brazilian-Portuguese version. Objective: To determine the construct validity and reproducibility of a Brazilian-Portuguese version of the FSS in patients with PD. Methods: In a cross-sectional study, a Portuguese-language version of the FSS was applied to 30 patients with PD (62 \pm 11 years-old). The Parkinson's disease questionnaire (PDQ-39) was used as the validation criterion, while the Hoehn and Yahr scale, the Unified Parkinson's Disease Rating Scale (UPDRS), and the Beck Depression Inventory were employed to analyze the correlations with the FSS score. Results: The test-retest intraclass correlation coefficient was 0.91 ( $p<0.01)$ for the Brazilian-Portuguese version of the FSS score, which was highly correlated with the PDQ-39 overall score $(r=0.93 ; p<0.01)$ and the Beck Depression Inventory $(r=0.75 ; p<0.01)$. It showed a correlation with the Hoehn and Yahr scale $(r=0.40 ; p=0.02)$, and with the UPDRS as well $(r=0.45, p=0.01)$. Conclusions: The Brazilian-Portuguese version of the FSS is valid and reproducible for using in Brazilian patients with PD.
\end{abstract}

Key words: Fatigue Severity Scale, fatigue, validation, quality of life.

\section{RESUMO}

A Fatigue Severity Scale (FSS-BR) é uma das mais usadas para avaliação da fadiga na doença de Parkinson e até hoje não foi validada para o português no Brasil. Objetivo: Determinar a validade de construto e a reprodutibilidade da versão brasileira da (FSS-BR) em pacientes com doença de Parkinson. Métodos: Em um estudo de corte transversal, a versão brasileira da Fatigue Severity Scale foi aplicada em 30 pacientes com doença de Parkinson (62 11 anos). O questionário de qualidade de vida da doença de Parkinson (PDQ-39) foi utilizado como critério de validação, assim como a escala Hoehn e Yahr (HY), a Escala de Graduação Unificada da Doença de Parkinson (UPDRS) e o Inventário de Depressão de Beck (BDI) foram empregados para analisar as correlações com a FSS-BR. Resultados: O coeficiente de correlação intraclasse foi $0,91(p<0,01)$ para a versão brasileira do escore da FSS, que foi muito correlacionado com o escore total do $P D Q-39(r=0,93 ; p<0,01)$ e com o $\operatorname{BDI}(r=0,75 ; p<0,01)$; demonstrou também correlação com a escala de gravidade HY ( $r=0,40 ; p=0,02)$, e com a escala UPDRS ( $r=0,45, p=0,01)$. Conclusões: A FSS-BR mostrou-se válida e reprodutível para uso em pacientes brasileiros com doença de Parkinson.

Palavras-Chave: Fatigue Severity Scale, fadiga, validação, qualidade de vida.

Fatigue is an important nonmotor symptom affecting approximately $58 \%$ of the patients with Parkinson's disease $(\mathrm{PD})^{1,2}$. It is present from the earliest stages of the disease and constitutes one of its three most disabling symptoms, with a significant negative impact on the patient's quality of life ${ }^{3-5}$.

Several fatigue-rating instruments have been used in published studies in $\mathrm{PD}^{6}$. The Fatigue Severity Scale $(\mathrm{FSS})^{7}$ is one of the most frequently used self-rating scales for fatigue, and it has been strongly recommended for using in PD patients ${ }^{6}$. The FSS is a nine-item self-report questionnaire scale developed in 1989, which measures the impact of fatigue on activities of daily living. Grading of each item ranges from 1 to 7 , where 1 indicates strong disagreement and 7 , strong agreement ${ }^{7}$. The FSS has been translated into, and validated in, various languages, and shows good psychometric properties in PD. However, this instrument lacks a validated Brazilian-Portuguese version.

${ }_{1}^{1}$ Physical Therapist, PhD, Division of Neurology and Epidemiology, Universidade Federal da Bahia, Salvador BA, Brazil;

${ }^{2} \mathrm{MsC}$, Division of Neurology and Epidemiology, Universidade Federal da Bahia, Salvador BA, Brazil;

${ }^{3} \mathrm{MD}$, PhD, Division of Neurology and Epidemiology, Universidade Federal da Bahia, Salvador BA, Brazil.

Correspondence: Ailton Melo; Divisão de Neurologia e Epidemiologia, Universidade Federal da Bahia; Rua Augusto Viana s/n; 41830 -380 Salvador BA - Brasil; E-mail:asm@ufba.br

Support: Fundação de Amparo à Pesquisa da Bahia (FAPESB), Brazil.

Conflict of interest: There is no conflict of interest to declare.

Received 17 October 2011; Received in final form 05 March 2012; Accepted 13 March 2012 
The objective of the present study was to assess whether the FSS is a valid and reproducible instrument to evaluate fatigue in PD patients in Brazil.

\section{METHODS}

This was an observational, cross-sectional study that evaluated patients with the clinical diagnosis of PD, according to the PD Society Brain Bank criteria for idiopathic PD $(\mathrm{UK}-\mathrm{PDSBB})^{8}$. Patients with other neurological disorders, previous neurosurgery and dementia were excluded. The patients were recruited from the university medical care center from October 2010 through December 2010. All participants were evaluated through the Mini-Mental State Examination $(\mathrm{MMSE})^{9}$, and they were expected to achieve a score equals to, or above, 20, if they had no schooling and equals to, or above, 24 for subjects with some level of schooling. PD symptoms were evaluated through the Unified Parkinson's Disease Rating Scale (UPDRS) ${ }^{10}$ (subscales I, II and III) and Hoehn and Yahr modified scale $(\mathrm{HY})^{11}$, while depressive symptoms were assessed using the Beck Depression Inventory (BDI $)^{12}$. Quality of life was evaluated through the PD Quality of Life Questionnaire (PDQ-39) ${ }^{13}$. Also, demographic data were collected. The patients completed the Brazilian version of the Fatigue Severity Scale (FSS-BR). In the present study, backtranslation of the FSS was not necessary, since Doctor Krupp, which is the holder of the copyright of the original Englishlanguage scale ${ }^{7}$, granted us the rights to use a Portugueselanguage version of the FSS that was developed by her group. After this version, it was applied to a small sample of patients with PD, in order to identify terms or situations that could not be applied to Brazilians. Since there were no problems related to this scale, it was not necessary to make any changes to the questions. The present study was approved by the Ethics Committee of the Federal University of Bahia. All subjects provided informed consent.

The construct validity of the FSS-BR was evaluated based on the correlation of the FSS-BR score with the PDQ-39, HY modified scale, UPDRS, and BDI.

In order to determine the reliability of the FSS-BR, the scale was applied on two occasions, two weeks apart, by two well-trained interviewers. The assessments were denominated interview 1 (on both occasions to evaluate intra-observer reliability) and interview 2 (to evaluate inter-observer reliability). Interviews were conducted independently by the evaluators with a 30-minute interval between them.

\section{Statistical analysis}

Statistical analysis was performed using the Statistical Package for the Social Sciences (SPSS) software, version 16.0, for Windows. Descriptive statistics were used as required. Since data were ordinal, nonparametric statistical analysis was used. The internal consistency of the scale was assessed using Cronbach's coefficient alpha.

The construct validity of the FSS-BR in relation to the PDQ-39 was determined using Spearman's correlation coefficient, like the correlation of the FSS-BR with disease severity through the HY and UPDRS, and with depressive symptoms through the BDI.

The FSS-BR test-retest reproducibility was determined using the intraclass correlation coefficient (ICC), as well as the Wilcoxon's test, to detect differences between days 1 and 2 . The concordance between days 1 and 2 and interviews 1 and 2 was visually assessed using Bland and Altman plots. Statistical significance was set at $\mathrm{p}<0.05$.

\section{RESULTS}

Thirty patients were included in the study, and most of them were classified as having HY stages 1 and 2 (Table 1). No significant differences were found between the sex in age, disease duration, MMSE, UPDRS, HY, FSS-BR, PDQ-39 total score, and BDI. The clinical profile of the patients is depicted in Table 1. All patients were taking anti-Parkinsonian drugs, and none of the patients was excluded from the study.

The median for the FSS-BR was 4.4, ranging from 1.3 to 7. Regarding the FSS test time, there was no statistical difference between days 1 and 2 ( $p>0.05)$. The mean test times on days 1 and 2 were 4 and 3.5 minutes, respectively.

In the comparison between days 1 and 2, there were no significant differences in the FSS-BR $(\mathrm{p}=0.67)$, and the comparison between interviewers 1 and 2 showed no significant differences in the FSS-BR either $(\mathrm{p}=0.22)$.

The FSS-BR was strongly reproducible, with a significant correlation with the PDQ-39 domains and total score $(0.38<\mathrm{r}<0.93)$. Significant correlations were found between

Table 1. Characteristics of the patients with Parkinson's disease.

\begin{tabular}{lc} 
Variable & \\
\hline Age, years (mean, SD) & $62 \pm 11$ \\
Gender, F/M & $12 / 18$ \\
BMI, kg/m² (mean, SD) & $25 \pm 4.4$ \\
Duration of disease, years (mean, SD) & $7.6 \pm 6.5$ \\
MMSE (median, minimum-maximum) & $26.5(20-30)$ \\
UPDRS (median, minimum-maximum) & $32.5(12-86)$ \\
HY 1/2/2.5/3/4/5 (n) & $8 / 11 / 3 / 5 / 3 / 0$ \\
FSS-BR (median, minimum-maximum) & $4.4(1.3-7)$ \\
PDQ-39 overall score (median, minimum- & $212(111-328)$ \\
maximum) & $9(2-48)$ \\
BDI (median, minimum-maximum) & \\
\hline
\end{tabular}

MMSE: Mini-Mental State Examination; HY: Hoehn and Yahr modified scale; UPDRS: Unified Parkinson's Disease Rating Scale; FSS-BR: Brazilian version of the Fatigue Severity Scale; PDQ-39: Parkinson's disease questionnaire; BDI: Beck Depression Inventory. 
the FSS-BR score and the HY, UPDRS and BDI (Table 2), and excellent internal consistency was demonstrated by a Cronbach's coefficient alpha of 0.95 .

The ICC between days 1 and 2 was $0.91(p<0.01)$, and the Bland and Altman plots showed good test-retest concordance for the FSS-BR between days 1 and 2 ( $p=0.98$ ), and between interviews 1 and $2(\mathrm{p}=0.16)$, as seen in Figure.

\section{DISCUSSION}

Since most scales and questionnaires have been developed in English-speaking countries, a validation process is required before these instruments can be used in other countries. Therefore, for these instruments to be considered appropriate for clinical or research use, it is necessary to evaluate their reproducibility ${ }^{14}$.

The results of the present study demonstrated that the FSS-BR is valid and reproducible to use in assessing the fatigue of Brazilian patients with PD.

In the present study, the construct validity of the FSS-BR was shown by the strong and significant correlation of its score with the domain scores and overall score of the PDQ-39 and with the BDI score, as well as a moderate correlation with the HY and UPDRS scores. The FSS-BR shows excellent internal consistency, demonstrated by a Cronbach's coefficient alpha of 0.95 .

The absence of a statistically significant test-retest difference, together with the high ICC value of 0.91 and excellent internal consistency expressed by a Cronbach's coefficient alpha of 0.95 , demonstrates the reproducibility of the FSS-BR. The reproducibility of the FSS-BR was also visually assessed using Bland and Altman plots, which showed that the bias ratio (difference between days 1 and 2) was very close to zero; this demonstrated good concordance between days 1 and 2, and between interviews 1 and 2. Recently, a group of Brazilian researchers translated and validated the Parkinson's Fatigue Scale, which has shown an excellent internal consistency and correlation with the female sex, dysthymia, severity of depression, and daily somnolence ${ }^{15}$.

Regarding the FSS-BR test time, there was no statistical difference between days 1 and 2, although the test time on day 2 was shorter. We believe this minimal difference could be due to the fact that patients had better comprehension of the questions. The length of time was good, compared to the time required to administer the other questionnaire used in Brazil ${ }^{16}$.

The median for the FSS-BR was 4.4, ranging from 1.3 to 7. For the sake of comparison, similar data from the original study by Krupp and Pollina ${ }^{7}$, who evaluated the severity of fatigue, resulted in average values of 4.6 in PD patients.

The use of the FSS-BR could contribute more specifically to assess the impact of an intervention (physical and pharmacological) on the fatigue of patients with PD. Moreover,
Table 2. Correlations (Spearman's correlation test) between FSS-BR and PDQ-39 total score, BDI, HY and UPDRS.

\begin{tabular}{lcc} 
& $\mathrm{R}$ & $\mathrm{p}$-value \\
\hline PDQ-39 & & \\
Overall score & 0.93 & $<0.01$ \\
Mobility & 0.70 & $<0.01$ \\
Activities of daily living & 0.61 & $<0.01$ \\
Emotional well-being & 0.69 & $<0.01$ \\
Stigma & 0.51 & $<0.01$ \\
Social support & 0.61 & $<0.01$ \\
Cognition & 0.41 & $<0.05$ \\
Communication & 0.69 & $<0.01$ \\
Bodily discomfort & 0.38 & $<0.05$ \\
BDI & 0.75 & $<0.01$ \\
HY & 0.40 & 0.02 \\
UPDRS & 0.45 & 0.01 \\
\hline
\end{tabular}

PDQ-39: Parkinson's Disease Quality of Life Questionnaire; BDI: Beck Depression Inventory; HY: Hoehn and Yahr modified scale; UPDRS: Unified Parkinson's Disease Rating Scale; FSS-BR: Brazilian version of the Fatigue Severity Scale.
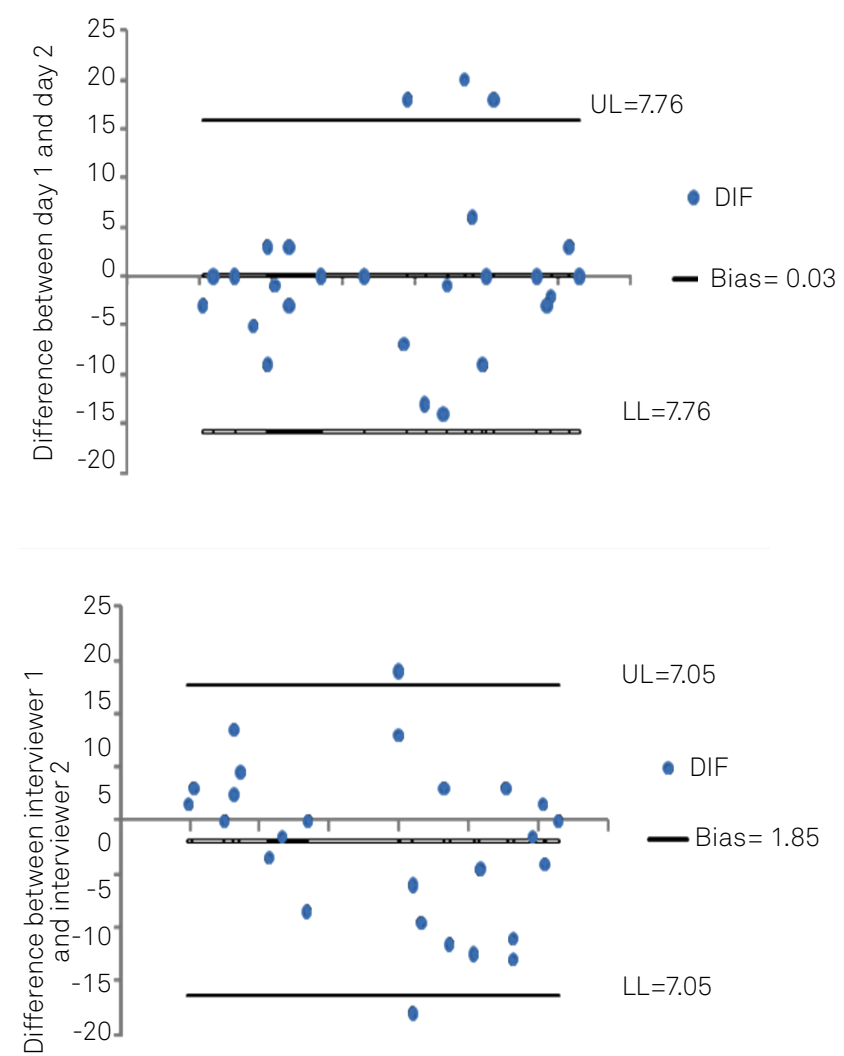

Figure. The Bland and Altman plots comparing the results obtained for the FSS-BR on test day 1 (D1) and on retest day 2 (D2); on interviewer 1 (I1) and interviewer 2 (I2). UL: upper limit; LL: lower limit. 
the identification of the major fatigue-related limitations in activities of daily living could lead to more specific interventions in the rehabilitation process.

In conclusion, the Portuguese-language version of the FSS showed to be valid and reproducible to use in Brazilian patients with PD.

\section{ACKNOWLEDGEMENTS}

We are grateful to L.B. Krupp for the authorization to use the FSS, and to the students Alaí Barbosa Paixão, Flávia Carine Santos, and Janine Ribeiro Camatti for their assistance in the present study.

\section{References}

1. Friedman JH, Brown RG, Comella C, et al. Fatigue in Parkinson's disease: a review. Mov Disord 2007;22:297-308.

2. Alves G, Wentzel-Larsen T, Larsen JP. Is fatigue an independent and persistent symptom in patients with Parkinson disease? Neurology 2004;63:1908-1911.

3. Havlikova E, Rosenberger J, Nagyova J, et al. Impact of fatigue on quality of life in patients with Parkinson's disease. Eur $J \mathrm{Neurol}$ 2008;15:475-480.

4. Herlofson K, Larsen JP. Influence of fatigue on health-related quality of life in patients with Parkinson's disease. Acta Neurol Scand 2003;107:1-6.

5. Martinez-Martins P, Catalan MJ, Benito-Leon J, et al. Impact of fatigue in Parkinson's disease: the fatigue impact scale for daily use (D-FIS). Qual Life Res 2006;15:597-606.

6. Friedman JH, Alves G, Hagell P, et al. Fatigue ranking scales critique and recommendations by the Movement Disorders Society Task Force on Rating Scales for Parkinson's Disease. Mov Disord 2010;25:805-822.

7. Krupp LB, Pollina DA. Mechanisms and management of fatigue in progressive neurological disorders. Curr Opin Neurol 1996;9:456-460.

8. Hughes AJ, Daniel SE, Kilford L, et al. Accuracy of clinical diagnosis of idiopathic Parkinson's disease: a clinico-pathological study of 100 cases. J Neurol Neurosurg Psychiatry 1992;55:181-184.

9. Folstein MF, Folstein SE, McHugh PR."Mini-Mental State": a practical method for grading the cognitive state of patients for the clinician. $J$ Psychiatr Res 1975;12:189-198.

10. Movement Disorders Society Force on Rating Scales for Parkinson's Disease. The Unified Parkinson's Disease Rating Scale (UPDRS): status and recommendations. Mov Disord 2003;18:738-750.

11. Hoehn MM, Yahr MD. Parkinsonism: onset, progression and mortality. Neurology 1967;17:427-442.

12. Gorenstein C, Andrade L. Validation of a Portuguese version of the Beck Depression Inventory and the State-Trait Anxiety Inventory in Brazilian subjects. Braz J Med Biol Res 1996;29:453-457.

13. Jenkinson C, Peto V, Fitzpatrick R, et al. Self-reported functioning and well-being in patients with Parkinson's disease: Comparison of the Short-form Health Survey (SF-36) and the Parkinson's disease Questionnaire (PDQ-39). Age Ageing 1995;24:505-509.

14. Guillemim F, Bombardier C, Beaton D. Cross-cultural adaptation of health-related quality of life measures: literature review and proposed guidelines. J Clin Epidemiol 1993;46:1417-1432.

15. Kummer A, Scalzo P, Cardoso F, et al. Evaluation of fatigue in Parkinson's disease using the Brazilian version of Parkinson's Fatigue Scale. Acta Neurol Scand 2011;123:130-136.

16. Chiari A, Sardim CCS, Natour J. Translation, cultural adaptation and reproducibility of the Cochin Hand Functional Scale questionnaire for Brazil. Clinics 2001;66:731-736. 